\title{
Analisis Pendidikan Islam dalam Puasa Ramadhan
}

\author{
Abd Misno \\ Institut Agama Islam Sahid (INAIS) Bogor \\ Email:drmisnomei@gmail.com
}

\begin{abstract}
Perfection of Islam in various sharia rules has two values, namely the value of worship and the value of muamalah. Fasting is an attempt to distance themselves from despicable acts and violates the provisions of Islamic teachings. Fasting is not only oriented toward physical acts of worship, but also acts of spiritual worship that can save and prosper the people, both physically and spiritually, in this world and the hereafter. The study in this study uses the literature method with descriptive analysis. Based on the results of the study regarding the value of Islamic education in Ramadan fasting, it was found that the value of Islamic education in fasting consists of two things, namely honesty and patience.

Keywords: Islamic Education, Ramadan Fasting, Honesty, Patience
\end{abstract}

\section{Pendahuluan}

Islam adalah agama yang sempurna, kesempurnaannya tercermin dari pengaturan seluruh sendi kesempurnaan kehidupan manusia. ${ }^{1}$ Islam juga mengatur tidak hanya masalah-masalah yang bersifat dzahir namun juga mengatur mengenai hal-hal yang bersifat batin seperti bagaimana cara memperoleh ketenteraman dan kebahagiaan di dunia dan di akhirat dan rahmat seluruh alam (rahmatan-lil'alamin). Oleh karenanya, di dalam syariat pasti ada manfaat, di setiap sesuatu yang bermanfaat (tentu dalam kacamata manusia) belum tentu hal tersebut sesuai syariat. ${ }^{2}$

Kesempurnaan Islam terlihat dalam berbagai aturan syariah yang selalu memiliki dua nilai-nilai, yaitu nilai-nilai ibadah dan nilai-nilai muamalah. Nilai-nilai ibadah yaitu setiap syariat Islam memiliki nilai-nilai spiritual sebagai bentuk peribadahan kepada Allah SWT. Adapun nilai-nilai muamalah adalah nilai-nilai yang bersifat keduniaan yang berkaitan dengan manfaat keduniaan bagi manusia.

Salah satu dari ibadah dalam Islam yang mengandung banyak hikmah adalah ibadah puasa. Puasa dalam al- Qur'an disebut dengan kata صيام, berakar dari kata yang bermakna menahan, berhenti, dan tidak bergerak. Manusia yang berupaya menahan diri dari suatu aktifitas, apapun aktifitas itu dinamai صائم (orang yang berpuasa). Pengertian kebahasaan ini dipersempit maknanya oleh hukum syari'at, sehingga panya

1 Peryataan ini terkait erat dengan konsep insan kamil, Hasan Langgulung menyebut insan kamil dengan sebutan insan shaleh, yang merupakan tujuan tertinggi dari pendidikan Islam. Membentuk insan shaleh adalah berusaha mengembangkan manusia yang menyembah dan bertaqwa kepada Allah, manusia yang penuh keimanan dan ketaqwaan, iman dan taqwannya kepada Allah dapat dibuktikan dengan amal perbuatan yang dilakukannya. Selain itu, segala fikiran yang tergores dan segala perasaan yang berdetak dijantungnya selalu mengagungkan asma Allah. Ciri-ciri dari insan shaleh seperti memiliki sikap terbuka pada alam dan mencari rahasia serta hikmahnya, ia bekerja tidak sekedar kerja namun kerjanya dianggap ibadah, berprinsip hanya kepada Allah dan memiliki rasa kasih sayang kepada sesama. Lihat detailnya Hasan Langgulung, Pendidikan Islam Menghadapi Abad Ke-21, (Jakarta: Pustaka al-Husna, 1998), 137

2 Miftah Faridl, Puasa: Ibadah Kaya Makna, Jakarta: Gema Insani, 2007), 1. 
digunakan untuk "menahan diri dari makan, minum, dan berhubungan badan dengan pasangan dimulai dari terbitnya fajar hingga terbenamnya matahari".

Seorang muslim dianggap sah puasanya menurut pandangan ahli fiqih, asalkan ia mampu menahan diri dari makan, minum, berhubungan biologis dan mengerjakan perbuatan yang membatalkan puasa dari terbitnya fajar sampai terbenamnya matahari. Namun hakekat puasa tidak hanya sekadar menahan diri dari nafsu perut dan nafsu syahwat tersebut, tetapi ada yang lebih substansial yaitu menahan atau mengendalikan diri dari segala keinginan hawa nafsu yang dapat menjerumuskan manusia kepada kerusakan dan kebinasaan. Karena itu menurut Islam, ibadah puasa adalah menjauhkan diri dari perbuatan-perbuatan tercela dan melanggar ajaran Islam. Dengan kata lain puasa bukan sekadar amal ibadah fisik, melainkan juga amal ibadah rohani yang dapat menyelamatkan dan menyejahterakan manusia, baik kehidupan lahir maupun batin, di dunia dan akhirat. ${ }^{4}$

Kemampuan untuk menahan dan mengendalikan diri ini tidaklah semata diraih begitu saja, tetapi memerlukan proses latihan atau pendidikan secara terus menerus, teratur, dan mengikuti prosedur tertentu. Karena itu jangka waktu pelaksanaan ibadah puasa Ramadhan didesain selama satu bulan agar menimbulkan efek positif dan mencapai sasaran yang diinginkan, yaitu taqwa. Taqwa adalah kondisi jiwa seseorang yang penuh dengan kesadaran akan kehadiran Allah SWT yang Maha Mengawasi dalam segenap aktifitasnya, di mana saja dan kapan saja, sehingga mendorong dirinya untuk selalu patuh dan taat mengerjakan segala perintah dan menjauhi laranganNya. Taqwa berasal dari dalam diri, karena itu ia sangat bersifat pribadi. ${ }^{5}$

Beberapa nilai-nilai pendidikan penting yang bisa digali dari pelaksanaan ibadah puasa diantaranya: pertama, puasa mengajari kita untuk senantiasa menahan dan

3 Muhammad Quraish Shihab, Membumikan al-Qur'an (Bandung: Mizan, 2009), 45. Lihat juga Ahmad Syalaby, Islam dalam Timbangan, Terj, Abu Laela \& Muhammad Tohir, (Bandung: PT. Al Maarif, 1982), 190.

${ }^{4}$ Ali Wasil El Helwany, Fasting: a Great Medicine (Manfaat Luar Biasa Puasa: Medis, Psikologis dan Spiritual Puasa Wajib ataupun Sunat, Peterj.: Hadiri, dkk., (Depok: IIMaN, 2008), 44. Hal ini yang sampai saat ini masih menjadi problematika dalam genealogi pendidikan Islam, yaitu akar filosofis dikotomi. Istilah lain dari dikotomi ilmu yang lebih menukik pada akar ilmu adalah pandangan dari A. Malik Fadjar yang mengistilahkan dikotomi ini dengan hellenis untuk ilmu umum atau ilmu modern dan semitis untuk ilmu agama. Gagasan hellenis berasal dari Yunani klasik yang ciri menonjolnya memberikan porsi yang amat besar terhadap otoritas akal, mengutamakan sikap rasional serta lebih menyukai ilmu-ilmu sekuler. Sedangkan gagasan semitis mewarnai alam pikiran kaum agamawan, terutama agama Yahudi dan Nasrani yang mendahului Islam, dengan ciri memberikan porsi yang amat besar kepada otoritas wahyu, sikap patuh terhadap dogma serta berorientasi kepada ilmuilmu keagamaan. Lihat detainya dalam A. Malik Fadjar, Reorientasi Pendidikan Islam, (Jakarta: Yayasan Pendidikan Islam Fajar Dunia, 1999), 99-100.

${ }^{5} \mathrm{Hal}$ ini secara eksplisit termaktub dalam QS. al-Baqarah ayat 183. Di mana Ibnu Katsir ketika memberikan ulasan pada ayat ini menjelaskan bahwa ayat ini ber-khitab kepada orang-orang mukmin dan memerintahkan kepada mereka berpuasa, yaitu menahan diri dari makan dan minum serta bersenggama dengan niat yang ikhlas karena Allah. Karena di dalam berpuasa terkandung hikmah membersihkan jiwa, menyucikannya serta membebaskannya dari endapan-endapan yang buruk (bagi kesehatan tubuh) dan akhlaq-akhlaq yang rendah. Bahkan puasa juga mengandung hikmah menyucikan tubuh dan mempersempit jalan-jalan setan. Al-Imam Abul Fida Isma'il Ibnu Katsir ad-Dimasyqi, Tafsir Ibnu Katsir, Peterj.: Bahrun. Pembacaan lebih terkait dengan takwa, lihat Dawam Raharjo, Ensiklopedi al-Qur'an, (Jakarta: Paramadina, 1996), 155; Yusuf al-Qardawi, Bagaimana Berinteraksi dengan al-Qur'an, terj. Kathur Suhardi, (Jakarta: Pustaka al-Kautsar, 2003), 16-19. 3; Nurcholis Madjid, Islam Doktrin dan Peradaban, (Jakarta: Paramadina, 2000), 45-46 
mengendalikan diri. Karakter ini sangat dibutuhkan bukan hanya untuk pejabat, tetapi juga untuk rakyat, pelajar, guru, pegawai, pengusaha, dan sebagainya.

Kedua, ketika berpuasa kita juga dilatih dan ditempa untuk sabar, peduli akan sesama, rajin dalam beribadah dan aktivitas-aktivitas positif lainnya, disiplin dan peneladanan sifat-sifat Tuhan kepada diri manusia. Karakter sabar, disiplin, rajin dan peduli ini, sangat penting perannya guna membawa bangsa bangkit dari krisis berkepanjangan. Sikap sabar dan tabah juga akan menempa setiap pribadi bangsa untuk berlapang dada ketika segenap usaha yang dilakukan, belum menemukan titik keberhasilan.

Ketiga, puasa mengajari kita untuk memiliki kepekaan (sense of responsibility) sensibilitas dan tanggung jawab sosial maupun pribadi. Salah satu hikmah puasa adalah penanaman solidaritas sosial dengan anjuran berbuat baik sebanyak-banyaknya, terutama dalam bentuk tindakan menolong beban kaum fakir miskin. Jika hal ini bisa terus berjalan pada waktu lain di luar bulan puasa, maka akan menjadi karakter bangsa yang patut disyukuri. ${ }^{6}$ Tafsir yang lebih luas, solidaritas sosial yang terpancar dalam diri setiap pribadi muslim, menjadi bukti menyatunya keimanan dan amal saleh (perbuatan kebajikan). Dengan kata lain, puasa yang mulanya merupakan implementasi dari rukun agama semata, kemudian menjadi sebuah laku sosial yang sangat konstruktif. Karakter utama inilah yang diharapkan mampu menempa setiap pribadi bangsa sehingga menjadi pendulum perubahan dan perbaikan.

Keempat, melalui puasa sebulan penuh umat Islam akan dilatih, digembleng mempererat dan memperkokoh persaudaraan, senasib-sepenanggungan, mencintai dan menyayangi keluarga, memakmurkan tempat-tempat ibadah dan sebagainya.

Jika dilihat hikmah-hikmah yang terdapat dalam pelaksanaan Ibadah puasa tersebut sangat erat kaitannya dengan dunia pendidikan. Pendidikan pada dasarnya adalah usaha untuk mengembangkan segala potensi dalam diri manusia, baik potensi jasmani maupun potensi rohani. ${ }^{8}$

Sebagaimana dikatakan Hasan Langgulung bahwa tujuan-tujuan pendidikan Islam harus mampu mengakomodasikan tiga fungsi utama dari agama, yaitu fungsi spiritual yang berkaitan dengan akidah dan iman, fungsi psikologis yang berkaitan dengan tingkah laku individual termasuk nilai-nilai yang menyangkut derajat manusia ke derajat yang lebih sempurna, dan fungsi sosial yang berkaitan dengan aturan sosial yang menghubungkan manusia dengan manusia lain atau masyarakat di mana masing-masing memiliki hak-hak dan tanggungjawab untuk menyusun masyarakat yang harmonis dan seimbang. ' Berdasarkan uraian diatas dapat disimpulkan bahwa dalam praktek ibadah dalam Islam memiliki nilai-nilai pendidikan. Demikian pula dalam ibadah puasa terdapat nilai-nilai pendidikan yang bisa dilaksanakan dalam proses belajar-mengajar di sekolah.

6 Tentang keberagamaan ini lihat detailnya Sulthan Ahmad, Dimensi Pengalaman Beragama: Sebuah Tela'ah Fenomenologis dan Antropologis, dalam Jurnal Tajdid Vol. 16, No. 1 Juli 2013, 127-140.

7 Zakiah Darajat, Puasa Meningkatkan Kesehatan Mental, (Jakarta: Ruhama, 1993), 37 2009), 23

8 Beni Ahmad Saebani dan Hendra Akhdiyat, Ilmu Pendidikan Islam, (Bandung: Pustaka setia, 21

${ }^{9}$ Hasan Langgulung, Beberapa Pemikiran Tentang Pendidikan Islam, (Bandung: PT. Al Ma’arif, 1980), 


\section{Metode Penelitian}

kajian ini yang menggunakan pendekatan kualitatif dengan jenis riset studi pustaka (library research). Kajian riset ini diarahkan untuk menguraikan aspek pendidikan Islam dalam puasa Ramadhan. Metode Analisis data yang digunakan dalam penelitian ini adalah deskriptif-analitis, melalui proses induksi-interprtetasi-konseptualisasi. Analisis data yang demikian, mengikuti apa yang dikemukakan Bogdan yakni analisis data kualitatif merupakan proses mencari dan menyusun secara sistematis data yang diperoleh dari hasil wawancara, catatan lapangan, dan bahan-bahan lain, sehingga dapat dipahami dengan mudah, dan temuannya dapat diinformasikan kepada orang lain. ${ }^{10}$

\section{Hasil dan Pembahasan}

\section{A. Analisis Nilai-Nilai Pendidikan dalam Ibadah Puasa Ramadhan}

\section{Puasa Membentuk Kejujuran}

Perilaku jujur adalah perilaku yang mulia. Namun di zaman sekarang ini, perilaku ini sangat sulit ditemukan. Kejujuran telah banyak dicampakkan dari tata pergaulan sosial-ekonomi-politik dan disingkirkan dari bingkai kehidupan manusia. Fenomena ketidakjujuran benar-benar telah menjadi realitas sosial yang menggelisahkan.

Secara psikologis, kejujuran mendatangkan ketentraman jiwa. ${ }^{11}$ Sebaliknya orang yang tidak jujur akan tega menutup-nutupi kebenaran dan tega melakukan kedzaliman terhadap hak orang lain. Sedangkan ketidakjujuran selalu meresahkan masyarakat, yang pada gilirannya mengancam stabilitas nasional. Berlaku jujur, sungguh menjadi bermakna pada masa sekarang, masa yang penuh dengan kebohongan dan kepalsuan. Jujur berarti berkata yang benar yang bersesuaian antara lisan dan apa yang ada dalam hati. Jujur secara bahasa dapat berarti perkataan yang sesuai dengan realita dan hakekat sebenarnya. ${ }^{12}$ Hawwa, 2002).

Allah SWT dalam beberapa ayat telah memerintahkan untuk berlaku jujur, diantaranya pada firman Allah SWT:

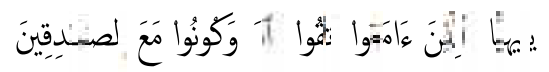

Hai orang-orang yang beriman bertakwalah kepada Allah, dan hendaklah kamu bersama orang-orang yang benar. QS. At-Taubah: 119

Jujur adalah satunya suara hati, ucapan dan perbuatan, dan pastilah tidak ada yang rela dikatakan bohong atau disamakan dengan perilaku hewan yang tidak memiliki akal dan pikiran. Jujur mencerminkan sikap hati yang menggambarkan ketaatan seseorang kepada Allah dan Rasul-Nya. ${ }^{13}$ Riwayat dari

10 Muslimin Machmud, Tuntunan Penulisan Tugas Akbir Berdasarkan Prinsip Dasar Penelitian Ilmiah (Malang: Selaras, 2016). 75

${ }^{11}$ Toto Tasmara, Membudayakan Etos Kerja, (Jakarta: Gema Insani, 2002), 81.

12 Said Hawwa, Tazkiyatun Nafs Intisari Ibya Ulumudin, (Jakarta: Darus Salam, 2005), 18 2010), 119.

13 Ahmad Hatta, Tafsir Qur'an Per Kata, Surat At-Taubah, Jakarta: Magfirah Pustaka, Agustus 
sahabat Abdullah bin Mas'ud juga dijelaskan keutamaan sikap jujur dan bahaya sikap dusta. Ibn mas'ud menuturkan bahwa Nabi SAW, yang artinya:

Hendaklah kalian senantiasa berlaku jujur, karena sesungguhnya kejujuran akan mengantarkan pada kebaikan dan sesungguhnya kebaikan akan mengantarkan pada surga. Jika seseorang senantiasa berlaku jujur dan berusaha untuk jujur, maka dia akan dicatat di sisi Allah SWTsebagai orang yang jujur. Berhati-hatilah kalian dari berbuat dusta, karena sesungguhnya dusta akan mengantarkan kepada kejahatan dan kejahatan akan mengantarkan kepada neraka. Jika seseorang suka berdusta dan erupaya untuk berdusta, maka ia akan dicatat di sisi Allah SWT sebagai pendusta. (HR. Muslim).

Istilah jujur bisa berlaku untuk beberapa makna, di antaranya adalah: pertama, Jujur dalam perkataan. Setiap orang harus menjaga perkataannya, tidak berbicara kecuali yang benar. Jujur dalam perkataan merupakan jenis jujur yang paling terkenal dan jelas. Seseorang harus menghindari perkataan yang dibuatbuat, karena itu termasuk jenis dusta, kecuali jika ada keperluan yang mendorongnya berbuat begitu dan dalam kondisi tertentu yang bisa mendatangkan maslahat.

Kedua, Jujur dalam niat dan kehendak. Jujur dalam hal ini dikembalikan kepada keikhlasan, yaitu tidak adanya pendorong dalam berbagai amal perbuatannya kecuali Allah SWT. Jika amalannya ternodai bagian-bagian nafsu, maka gugurlah kejujuran niatnya dan pelakunya bisa dikategorikan orang yang berdusta.

Ketiga, Jujur dalam 'azam (tekad, hasrat). Seseorang terkadang mendahulukan 'azam (tekad, hasrat) daripada amal perbuatannya. Seperti seseorang yang berkata pada dirinya, "Jika Allah SWTmengaruniakan harta kepadaku niscaya aku akan menginfakkan $20 \%$ dari keseluruhan harta". Atau seseorang yang mengatakan: "Jika Allah SWTmengaruniakan kekuasaan sebagai Gubernur niscaya aku akan berbuat adil terhadap seluruh masyarakat dan tidak bermaksiat kepada Allah SW'T". ${ }^{14}$

Tekad ini kadang mendapat dukungan dari dalam dirinya sehingga menjadi tekad yang benar (sadiq), dan terkadang dalam tekadnya itu terdapat semacam kecenderungan, keraguan dan kelemahan yang bertentangan dengan kebenaran tekadnya. Jika tekad tersebut memudar dan tidak ditepatinya maka orang tersebut masuk kategori pendusta. Allah SWT berfirman:

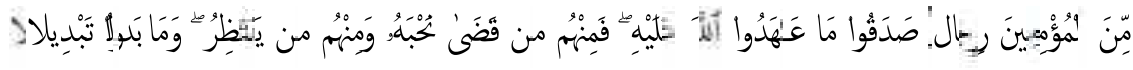

Di antara orang-orang mukmin itu ada orang-orang yang menepati apa yang telah mereka janjikan kepada Allah, maka di antara mereka ada yang gugur, dan di antara mereka ada (pula) yang menunggu-nunggu dan mereka tidak sedikitpun tidak merubah (janjinya). QS. Al-Ahzab: 23.

${ }_{14}$ Pembacaan lebih lanjut, lihat Anas Salahudin dan Irwanto Alkriencienchi, Pendidikan Karakter, (Jakarta: CV Pustaka Setia, 2013). 43. 


\section{Puasa Membentuk Kesabaran}

Puasa Ramadhan merupakan media yang sangat efektif untuk melatih kesabaran. Betapa manusia yang beriman selama satu bulan dilatih untuk bersabar, sabar menahan makan dan minum, sabar untuk menahan nafsu syahwat, sabar untuk menahan amarah dan angkara murka, sabar untuk menahan jiwa dan raga dari melakukan tindakan yang dapat mengurangi tindakan yang dapat mengurangi nilai-nilai pahala puasa, bersabar untuk bangun malam, untuk qiyam al-lail, untuk sahur dan lain sebagainya.

Begitu banyak hadis Nabi yang menyebutkan bahwa orang yang tidak bersabar menahan nafsu, marah dan angkara murka serta jiwa dan raga dari perbuatan yang dilarang Allah, maka Allah SW'Ttidak membutuhkan darinya dari puasa menahan makan dan minum. Nabi SAW bersabda:

Barang siapa yang tidak bisa meninggalkan perkataan dan perbuatan dusta maka Allah SWTtidak butuh terhadap amalan dia meninggalkan makanan dan minumannya. HR. Bukhari, Abu Dawud dan Thirmidzi.

Hadis di atas menegaskan akan peringatan dan larangan bagi orangorang yang berpuasa untuk melakukan tindakan yang dilarang dan dapat berkurang nilai-nilai puasa, yang mana inti dari itu semua adalah dengan bersabar. Sabar adalah inti dari puasa, karena itulah Rasulullah menyampaikan dalam khutbahnya untuk menyambut Ramadhan: ...Yaitu (bulan Ramadhan) adalah bulan kesabaran, dan sabar ganjarannya adalah surge (HR. Ibnu Khuzaimah).

Kesabaran adalah salah satu ciri mendasar orang yang bertaqwa. Oleh karenanya, dengan puasa Ramadhan seharusnya kita tumbuh kembangkan kesabaran agar mampu melaksanakan perintah Allah Swt baik dalam suka maupun duka di mana saja kita berada serta mampu menjauhi maksiat atau larangan-Nya sehingga menjadi manusia muttaqin.

Kata sabar berasal dari bahasa Arab صبر - صبرا yang memiliki makna tabah hati. ${ }^{15}$ Sabar secara terminologi bahasa artinya menahan dan mencegah diri. Hal ini dapat ditelusuri lebih lanjut dari akar kata yang terdiri dari huruf e dan Maknanya berkisar pada tiga hal, yaitu menahan, ketinggian sesuatu, dan sejenis batu. Dari makna pertama, lahir makna "konsisten dan bertahan" karena yang bertahan, menahan pandangannya pada satu sikap. Seseorang yang menahan gejolak hatinya dinamai 'sabar'. Dari makna kedua, lahir kata subr yang berarti puncak sesuatu. Merujuk pada makna ketiga, muncul kata subrah, yaitu batu yang kukuh lagi kasar, atau 'potongan besi'. Ketiga makna tersebut dapat saling berkait jika pelakunya manusia. Seorang yang sabar akan menahan diri dan untuk itu, ia memerlukan kekukuhan jiwa dan mental baja agar dapat mencapai ketinggian yang diharapkan.

Ensiklopedia Islam menyatakan bahwa sabar adalah menahan diri dalam menanggung suatu penderitaan, baik dalam menemukan sesuatu yang tidak

15 A.W. Munawwir, Kamus Al-Munawwir Arab-Indonesia Terlengkap, (Surabaya : Pustaka Progressif, 1997. 
diingini maupun dalam bentuk kehilangan sesuatu yang disenangi. ${ }^{16}$ Sabar adalah jalan dalam mencapai keberhasilan dan kebahagiaan. Sabar adalah suatu keutamaan yang diperlukan oleh manusia, baik dalam urusan agama maupun dunianya. Keadaan manusia itu adakalanya harus bersabar terhadap perintah yang wajib dilakukan dan dilaksanakan olehnya, larangan yang harus ditinggalkannya, menerima takdir yang tak terelakkan yang menimpa dirinya, dan nikmat yang mengharuskannya bersyukur kepada Tuhan yang telah memberikannya.

Aplikasi sikap sabar dalam kehidupan keseharian, diantaranya adalah; pertama, Bersabar dalam menghadapi perbedaan pendapat. Terdapat sebuah ungkapan yang cukup populer, Ikhtilaf al ummah rahmatun (perbedaan pendapat di kalangan umat Islam adalah rahmat). Substansi hadis ini adalah perbedaan pendapat di antara umat Islam merupakan fitrah keagamaan, yang masingmasing orang atau golongan harus saling menghormati perbedaan yang ada. Pada konteks fiqih, sebagaimana dinyatakan Ibnu Taimiyah, terdapat kaidah ta'addud al-ibadah (keragaman tata cara ibadah), yang pada zaman Rasulullah SAW juga sudah terjadi, dan semuanya diamini oleh Nabi SAW.

Sebagian kalangan umat Islam, terdapat 'tradisi' saling menyesatkan, saling menyalahkan karena masih belum mau berlapang dada membuka cakrawala Islam yang sedemikian luas. Kesabaran dalam memelihara kerukunan antar umat Islam dan saling menghormati keragaman tata cara beribadah dan tradisi keagamaan, yang berasal dari tradisi lokal, bagi masing-masing pihak merupakan hal yang sangat berat.

Kedua, Bersabar dalam menghadapi kesulitan. Semua kesulitan dan kesempitan hidup, hendaknya dikembalikan kepada Allah. Segala kesulitan harus disikapi secara bijaksana, kita laksanakan kesabaran dengan mengerjakan sesuatu yang disukai Allah SWT, dan menahan diri dari melakukan sesuatu yang dibenciNya. Dengan kata lain sabar dalam hal ini adalah bertahan dalam mengerjakan sesuatu yang diperintahkan Allah SW'T, sebagai cara untuk keluar dari segala cobaan dan kesulitan, tidak mengambil jalan pintas yang dilarang Allah SWThanya demi segera hilangnya kesulitan. Allah SWT berfirman:

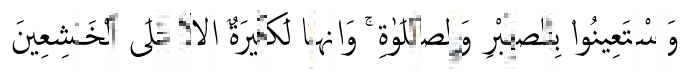

Dan mohonlah pertolongan (kepada Allah) dengan sabar dan shalat, dan (shalat) itu sungguh berat, kecuali bagi orang-orang yang khusuk. QS. alBaqarah: 45

Ketiga, Bersabar dalam kesempitan ekonomi. Kesempitan ekonomi atau kemiskinan, kadang membuat orang mengambil jalan pintas agar kebutuhan ekonomi tercukupi. Kemiskinan terkadang membuat orang lupa dan melalaikan kekuasaan Allah SWT serta norma keagamaan. Dari cara yang sederhana, seperti mencuri, merampok, sampai korupsi, menjadi bagian dalam kehidupan mereka.

${ }^{16}$ Ensiklopedi Islam 6. (Jakarta: PT Ichtiar Baru van Hoeve, 2006). 
Terkait dengan kemiskinan ini, Rasulullah SAW memberikan tuntunan bahwa sikap paling baik dan terpuji bagi orang yang berada dalam kesempitan ekonomi adalah dengan bersabar. Sabar dalam hal ini adalah menjauhi semua perbuatan tidak terpuji untuk memperoleh harta demi menutupi kemiskinannya. Rasulullah SAW bersabda:

Barangsiapa yang bersabar atas kesulitan dan himpitan kehidupannya, maka aku akan menjadi saksi atau pemberi syafaat baginya pada hari kiamat. HR. Thirmidzi.

Keempat, Sabar dalam mengerjakan ibadah. Dalam mengerjakan ibadah sehari-hari terkadang dirasakan berat, karenanya kita dituntut sabar dalam melaksanakannya dalam rangka taat kepada Allah. Ibadah adalah penghubung antara hamba dan penciptanya, ibadah merupakan sumber untuk mendapatkan kekuatan, ketabahan, ampunan, ketenangan, dan sarana membersihkan diri dari noda-noda dosa. ${ }^{17}$ Akan tetapi justru karena kedudukan ibadah yang sedemikian tinggi dan mulia dihadapan Allah, sangat berat dirasakan oleh sebagian besar orang dalam mengerjakannya.

Beribadah sebagai realisasi ketaatan kepada Allah SWTmembutuhkan kesabaran, karena secara tabi'atnya jiwa manusia enggan untuk beribadah dan berbuat ketaatan. Ditinjau dari penyebabnya, sedikitnya terdapat empat hal yang menyebabkan manusia sulit untuk bersabar dalam beribadah. Pertama karena malas, seperti dalam melakukan ibadah shalat, kedua merasa berat, seperti dalam menjalankan ibadah puasa, ketiga karena bakhil, seperti menunaikan zakat dan infak, keempat, karena ketiganya (malas, berat dan bakhil), seperti menunaikan ibadah haji.

Bersabar dalam menjalankan ibadah berarti tidak melalaikan Allah SWT pada saat melakukannya, tidak merasa malas dari mewujudkan beberapa persyaratan, rukun dan sunnah dalam pelaksanaannya. Ini termasuk kesabaran yang berat dan barangkali termasuk apa yang dimaksudkan Allah SWT dalam surah al-Ankabut: 58-59

Kelima, bersabar dalam menghadapi musibah dan cobaan. Kehidupan manusia di dunia, menurut sunnatullah adalah dalam rangka 'melampaui ujian', yang jika lulus, ia akan naik derajatnya dan mendapatkan kebahagiann di akhirat. Ujian dan cobaan itu untuk mengukur sejauh mana seseorang mengatakan "Aku beriman kepada Allah SWT" mampu membuktikan keimanannya itu. Cobaan yang nyata yang dituntut mewujudkan keimanan dan kesabaran adalah musibah kelaparan, kekurangan harta, meninggalnya anggota keluarga atau saudara, dan lain sebagainya. Allah SWT berfirman:

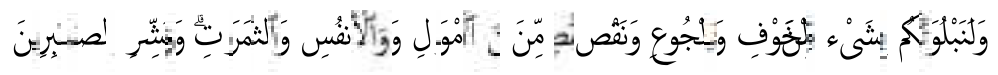

17 Al-Qaradhawi Yusuf, Fatwa-fatwa Kotemporer jilid 3, penerj. Abdul Hayyie alKattani, dkk, (Jakarta: Gema Insani Press, 2002) 
Dan pasti kami akan menguji kamu dengan sedikit ketakutan, kelaparan, kekurangan harta, jiwa, dan buah-buahan. Dan, sampaikanlah kabar gembira kepada orang-orang yang sabar. (QS. Al-Baqarah: 155)

Keenam, bersabar dengan keadaan cacat fisik. Tidak semua manusia dilahirkan dalam wujud yang sempurna, ada beberapa hamba Allah SWT yang diberi ujian berupa cacat fisik. Kecacatan fisik tidak harus dihadapinya dengan ratapan, atau menyalahkan takdir Tuhan. Semuanya lebih baik diterima dengan kesabaran. Nabi SAW telah menyampaikan berita gembira bagi orang yang kehilangan indra penglihatannya, bahwa Allah SW'T akan menggantinya dengan surga:

Sesungguhnya Allah SW'Ttelah berfirman kepadaku: Apabila Aku menguji hamba-Ku pada kedua anggota tubuh yang paling disayanginya (kedua matanya), lalu dia bersabar, niscaya Aku akan menggantikan keduanya untuk dia dengan surga. Orang yang mampu bersabar dengan kecacatan fisiknya selalu diberi kabar gembira bahwa hasil perolehan amal salehnya di dunia, nanti akan dinikmatinya di akhirat dengan surge (HR. Bukhari dan Baihaqi).

Seorang budak perempuan hitam penderita epilepsy mengadukan penyakit yang dialaminya kepada Nabi SAW berkata, "Sungguhnya aku sering tak sadarkan diri, aku khawatir, auratku sselalu terbuka. Maka doakanlah kepada Allah SWT untuk kesembuhanku". Nabi SAW menjawab:

Jika engkau mampu bersabar, bagimu surga. Namun, jika engkau menginginkan aku berdoa kepada Allah SWTuntuk kesembuhanmu, aku akan melakukannya. Wanita itu berkata, "Aku akan bersabar, tetapi doakanlah kepada Allah SWTagar auratku tidak terbuka saat aku tak sadarkan diri”. Nabi pun mendoakannya, dan diriwayatkan bahwa sesudah itu, apabila wanita tersebut tak sadarkan diri, auratnya tidak terbuka lagi (HR. Bukhari).

Berdasarkan hadis sebelumnya diperoleh pengertian bahwa sabar adalah budi pekerti yang bisa diraih, bukan sesuatu yang alami semata yang tidak bisa ditingkatkan.

Ketujuh, Bersabar ketika disakiti atau mengalami penghinaan. Merasa dihinakan, diejek sesama manusia, direndahkan dan sejenisnya, membutuhkan kesabaran. Sabar dalam hal ini adalah kelonggaran hati serta sikap memberi maaf kepada sesama. Dalam suatu peristiwa dikemukakan bahwa ada seorang laki-laki mengeluh kepada Rasulullah tentang perlakuan yang menghinakan dari tetangganya, kemudian Nabi SAW bersabda:

Tahanlah rasa sakit hatimu terhadapnya, dan besabarlah untuk (tidak) menyakitinya. Cukuplah dengan kematian yang (akan) memisahkan. (HR. Ibnu Najjar). 
Kesabaran adalah sebuah sikap hidup yang terpuji. Di antara faktor-faktor pendorong atau landasan kekuatan sikap kesabaran adalah nilai-nilai positif, yaitu:

a. Sabar membawa keberuntungan dunia dan akhirat. Kesabaran disebutkan oleh al-Qur'an, akan membawa keberuntungan bagi pelakunya, sebagaimana disebutkan dalam QS. Ali Imran: 200. Kesabaran dalam ayat ini bukanlah sekadar kesabaran biasa, melainkan kesabaran yang dilandasi keteguhan hati, daya istiqamah, karena percaya betul dengan janji kemenangan dari Allah. Kesabaran yang disertai keteguhan ini, terkait dengan keikhlasan pengabdian kepada Allah. Oleh karenanya, orang-orang ini selalu memiliki kewaspadaan yang tinggi, mereka juga selalu menggantungkan segalanya kepada Allah SW'Tmelalui ketakwaannya. $^{18}$ Agar kesabaran makin kukuh dalam hati sanubari manusia yang beriman, Allah SWT memberikan rujukan untuk meneladani para Nabi dan rasul yang memiliki keteguhan hati sangat istemewa, yang kemudian dikenal sebagai rasul ulul al-'azmi.

b. Sabar sarana memohon pertolongan kepada Allah. Salah satu cara 'mendekati' Allah SW'Tyang efektif adalah meneladani sifat-sifat Allah SWTsebagai sifat kita. Sifat-sifat Allah SWTyang tertuang dalam asma' al-husna kita terjemahkan menjadi akhlak keseharian kita. Sikap sabar adalah cerminan dari asma' al-husna, alsabur yang dapat kita teladani. Maka wajar jika Allah SWT menjadikan sabar (selain shalat) sebagai gantungan Allah SWTdalam menolong hamba-hamba-Nya (QS. Al-Baqarah: 45).

c. Anugerah khusus hanya diberikan kepada orang yang sabar. Allah SW'T telah menganugerahkan kepada orang-orang yang sabar tiga perkara yang tidak diberikan-Nya kepada selain mereka, yaitu ampunan, rahmat, dan hidayah-Nya, seperti diterangkan dalam ayat ini:

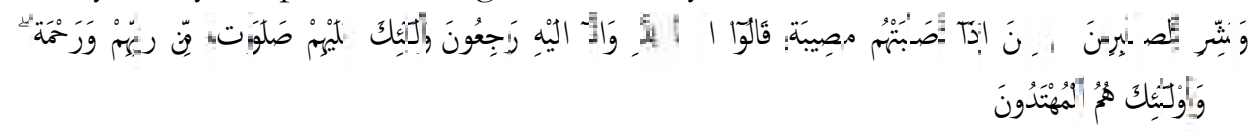

...Dan sampaikanlah kabar gembira kepada orang-orang yang sabar, (yaitu) orang yang apabila ditimpa musibah, mereka berkata "Inna lillahi wa inna ilaihi raji'un" (Sesungguhnya kami milik Allah SWT dan kepada-Nyalah kami kembali). Mereka itulah yang memperoleh ampunan dan rahmat dari Tuhannya, dan mereka itulah orang-orang yang mendapat petunjuk. QS. Al-Baqarah: 155-157

Jarang suatu amal mendapatkan tiga balasan sekaligus, yang balasan itu menggabungkan anugerah terbesar dari Allah, kecuali dengan kesabaran ini. Kesabaran yang menghasilkan tiga anugerah tersebut adalah kesabaran yang membuahkan kesadaran rohani, yakni keyakinan

${ }_{18}$ Pembacaan lebih lanjut lihat, Al-Ghazali, Imam, Taubat, Sabar dan Syukur, terj. Nur Nikmah, Jakarta: Tintamas, 1983; IQ. al-jauziyah, Nikmatnya Sabar, (Jakarta; Senayan Publishing. 2009). 
total bahwa semua berasal dari Allah, milik Allah SWTdan kembali kepada Allah. ${ }^{19}$

Tidak ada sisa apa-apa dalam diri hamba, semua yang ada pada dirinya hanya dipandang sebagai amanat, bukan milik. Ketika kita shalat, jangan merasa telah memberikan shalat itu kepada Allah. Demikian pula zakat, puasa, haji, dan segala amal saleh yang melibatkan harta benda serta raga. Semua itu hakekatnya hanya 'mengembalikan' barang Tuhan kepada Tuhan.

d. Orang yang bersabar adalah hamba pilihan Allah. Allah SWT menjadikan sabar dalam menghadapi berbagai musibah termasuk hal yang diutamakan dan kedudukan ini tidak mudah diraih oleh sembarang orang. Allah SWT berfirman:

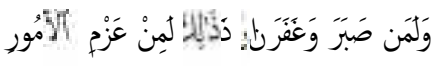

Tetapi barangsiapa bersabar dan memaafkan, sungguh yang demikian itu termasuk perbuatan yang mulia. QS. Asy-Syuraa: 43

e. Kejayaan dapat diraih dengan kesabaran. Kesabaran, dalam arti memiliki sikap kehati-hatian, penuh perhitungan, tidak tergesa-gesa, dan tidak emosional dalam menentukan segala sesuatu, akan membawa keberuntungan dan kejayaan. ${ }^{20}$ Allah SWT telah menjanjikan pertolongan dan memenangkan orang yang beriman sebelumnya, berkat kesabaran mereka, seperti yang disebutkan dalam firman Allah SWT.

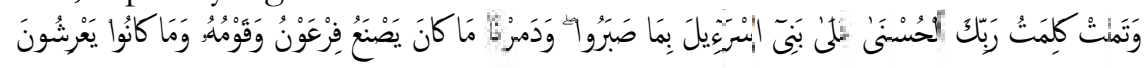

Dan telah sempurnalah firman Tuhanmu yang baik itu (sebagai janji) untuk Bani Israil disebabkan kesabaran mereka. Dan kami hancurkan apa yang telah dibuat Fir'aun dan kaumnya dan apa yang telah mereka bangun. QS. Al-A'raf: 137

Ayat tersebut di atas memberi gambaran kepada kita tentang umat Bani Israil pada zaman Nabi Musa. Mereka berada di bawah kezaliman Fir'aun dalam waktu yang cukup lama. Akan tetapi, mereka tetap tabah, sabar dan istiqamah dalam keimanan kepada Allah SW'Tsehingga Allah SWTmemberikan Taufik dan rahmat-Nya. Pada akhirnya, dengan berbagai cara dan strategi, yang dipandu dengan pertolongan Allah SW'Tmelalui mukjizat Nabi Musa, mereka memperoleh kemenangan.

\section{Catatan Akhir}

Berdasarkan pembahasan mengenai nilai-nilai pendidikan Islam dalam ibadah puasa Ramadhan, maka dapat disimpulkan bahwa: Nilai-nilai pendidikan Islam dalam ibadah puasa menjadi terwujud dalam diri manusia dicapai dengan sedikitnya dua hal, kejujuran dan kesabaran.

19 Muhammad Solikhin, The Power of Sabar (Solo: Tiga Serangkai, 2009), 155. Sebagai bahan perbandingan lihat Amin An-Naj)ar, Ilmu Jiwa dalam Tasawuf, Terj: Hasan Abrori. (Jakarta: Pustaka Azzam, 2001)

${ }^{20}$ Muhammad Solikhin, The Power of Sabar ....155, 167. 
Aktualisasi nilai kejujuran yang di ambil dari ibadah puasa dapat diwujudkan dengan kejujuran dalam perkataan, mengakui kesalahan, menepati janji, tidak bersumpah palsu, tidak mengurangi timbangan, tidak menyembunyikan kecacatan barang dalam perniagaan.

Aktualisasi nilai kesabaran yang diambil dari ibadah puasa dapat diwujudkan dalam bersabar menghadapi perbedaan pendapat, bersabar dalam menghadapi kesulitan, bersabar dalam kesempitan ekonomi, sabar dalam mengerjakan ibadah, bersabar dalam menghadapi musibah dan cobaan, bersabar dengan keadaan cacat fisik dan bersabar ketika disakiti atau mengalami penghinaan.

\section{Daftar Rujukan}

A.W. Munawwir. 1997. Kamus Al-Munawwir Arab-Indonesia Terlengkap, Surabaya : Pustaka Progressif.

Ahmad, Sulthan, Dimensi Pengalaman Beragama: Sebuah Tela'ah Fenomenologis dan Antropologis, dalam Jurnal Tajdid Vol. 16, No. 1 Juli 2013, 127-140.

Al-Bukhari, Abu Abdillah Muhammad bin Isma'il. 1993. Al-Jami' al-Sahih, Jilid 2. Kairo: Maktabah al-Salafiyah

Al-Ghazali, Abu Hamid Muhammad. 2005. Asrar al-Saum wa Asrar al-Zakat, terj. Muhammad al-Baqir, Rahasia Puasa dan Zakat. Bandung: Karisma

Al-San'ani, Muhammad bin Isma'il. tt. Subul al-Salam, jilid 2. Surabaya: Al-Hidayah

Al-Shaukani, Muhammad bin 'Ali bin Muhammad. tt. Nail al-Autar: jilid 4. Kairo; Mustafa al-Babi al-Halabi

Al-Tirmizi, Abu Isa Muhammad bin Isa. 1996. Al-Jami' al-Kabir, Jilid 2. Beirut: Dar alGharb al-islami

Ash-Shiddieqy, M. Hasbi. 2010. Pedoman Puasa, Semarang: Pustaka Rizki Putra

Asmara, Toto. 2002. Membudayakan Etos Kerja, Jakarta: Gema Insani

Azzam, Abdul Aziz Muhammad dan Abdul Wahhab Sayyed Hawwas. 2009. Al-Wasit fi al-Figh al-Tbadah, terj. Kamran As'at, dkk Fiqh Ibadah. Jakarta: Amzah

Bakhtiar, Laleh, ed. 2007. Ramadan Motivating Believers To Action: An Interfith Perspective, terj. Sari Meutia, Meraih Kemuliaan Ramadhan. Bandung: Mizan

Daradjat, Zakiah. 1993. Puasa Meningkatkan Kesehatan Mental, Jakarta: Ruhama

Fadjar, A. Malik. 1999. Reorientasi Pendidikan Islam. Jakarta: Yayasan Pendidikan Islam Fajar Dunia.

Faridl, Miftah. 2007. Puasa: Ibadah Kaya Makna, Jakarta: Gema Insani, 2007.

Ghazali. 1983. Imam, Taubat, Sabar dan Syukur, terj. Nur Nikmah, Jakarta: Tintamas

Hasan, M. Ali dan Mukti Ali. 2003. Kapita Selekta Pendidikan Islam. Jakarta: Pedoman Ilmu Jaya

Hatta, Ahmad. 2010. Tafsir Qur'an Per Kata, Surat At-Taubah, Jakarta: Magfirah Pustaka.

Hawwa, Sa'id Muhammad Daib. 2002. Al-Mustakblas fi Tazkiyah al-Anfus, terj. Aunur Rafiq Shaleh, Mensucikan Jiwa, Konsep Tazkiyatun Nafs Terpadu. Jakarta: Robbani Press.

Hawwa, Said. 2005. Tąkiyatun Nafs Intisari Ibya Ulumudin, Jakarta: Darus Salam

Helwany, Ali Wasil. 2008. Fasting: a Great Medicine (Manfaat Luar Biasa Puasa: Medis, Psikologis dan Spiritual Puasa Wajib ataupun Sunat, Peterj.: Hadiri, dkk., Depok: IIMaN

Ibn Kathir, Imad al-Din Abi al-Fida' Isma’il. 2000. Tafsir al-Qur'an al-"Azim. Kairo: Mu'assasah Qurtubah 
Imam Muslim, Abi al Husain bin al-Hajjaj. 1996. Sabih Muslim, Jilid 2. Riyadh: Dar 'Alam al-Kutub

Iqbal, Muhammad. 2007. Ramadan dan Pencerahan Spiritual. Jakarta: Erlangga

Jauziyah, IQ. 2009. Nikmatnya Sabar, Jakarta; Senayan Publishing.

Kusuma, Hembing Wijaya. 2007. Puasa itu Sehat. Jakarta: Gramedia Pustaka Utama

Langgulung, Hasan. 1980. Beberapa Pemikiran Tentang Pendidikan Islam, Bandung: PT. Al Ma'arif

Langgulung, Hasan. 1998. Pendidikan Islam Menghadapi Abad Ke-21, Jakarta: Pustaka alHusna

Langgulung, Hasan. 2009. Manusia dan Pendidikan: Suatu Analisa Psikologi dan Pendidikan. Jakarta: Pustaka al-Husna

Machmud, Muslimin. 2016. Tuntunan Penulisan Tugas Akbir Berdasarkan Prinsip Dasar Penelitian Ilmiah. Malang: Selaras

Madjid, Nurkholis. 1992. Islam Doktrin dan Peradaban, Sebuab Telaah Kritis tentang Masalab Keimanan, Kemanusiaan, dan Kemodernan. Jakarta: Paramadina

Malik, Muhammad Rusli. 2003. Puasa; Menyelami Arti Kecerdasan Intelektual, Spiritual dan Emosional di Bulan Ramadhani. Jakarta: Pustaka Zahrah

Muratta, Sichiko, dan William C. Chittick. 2005. The Vision of Islam, terj. Suharsono. Yogyakarta: Suluh Press

Najjar, Amin. 2011. Ilmu Jiwa dalam Tasawuf, Terj: Hasan Abrori. Jakarta: Pustaka Azzam.

Nina Armando, et. Al. 2005. Sabar, Ensiklopedi Islam, jilid 6. Jakarta: Ichtiar Baru Van Hoeve

Prawiro, Abdurrahman Misno Bambang, 2009. Islam Apa Adanya, Bogor: IPB Press.

Pusat Bahasa Departemen Pendidikan Indonesia. 2002. Kamus Besar Bahasa Indonesia. Jakarta: Balai Pustaka

Qaradhawi, Yusuf. 2005. Al-Tbadah fi al-Islam, terj. Abdurahim Ahmad dan Muhammad Muhtadi, Ibadah Dalam Islam, Jakarta: Akbar

Qaradhawi, Yusuf. 2010. Fiqh al-Siam, terj. Makruf Abdul Jalil, dkk, Fiqib Puasa, Solo: Era Intermedia

Qardawy, Yusuf. 2003. Bagaimana Berinteraksi dengan al-Qur'an, terj. Kathur Suhardi, Jakarta: Pustaka al-Kautsar

Rahardjo, Dawam. 2003. Ensiklopedi al-Qur'an, Jakarta: Paramadina

Saebani, Beni Ahmad dan Hendra Akhdiyat. 2009. Ilmu Pendidikan Islam, Bandung: Pustaka Setia

Salahudin, Anas dan Irwanto Alkriencienchi. 2013. Pendidikan Karakter, Jakarta: CV Pustaka Setia

Salim, Muhammad Ibrahim. 2009. al-Tadawa bi al-Siyam wa Mazayahu al-Adhimah, terj. Muhammad Jawis, The Miracle of Shaum (Mukjizat Puasa). Jakarta: Amzah

Samsul Nizar. 2002. Filsafat Pendidikan Islam: Pendekatan Historis, Teoritis dan Praktis. Jakarta: Ciputat Press

Sha'rani, Shaikh Mutawalli, al-Tadawi bi al-Siam, terj. A. Rusydi Wahab, Keistemewaan Puasa: Menurut Syari'at dan Kedokteran (Depok: Qultum media, 2006)

Shihab, M. Quraish. 2000. Wawasan Al Qur'an: Tafsir Maudhu'i Atas Pelbagai Persoalan Umat. Bandung: Mizan.

Shihab, M. Quraish. 2008. Menyingkap Tabir Ilabi Asmaul Husna dalam prespektif Al-Qur'an Jakarta: Lentera

Solikhin, Muhammad. 2009. The Power of Sabar. Solo: Tiga Serangkai. 
Sumantri, Jujun S. 2008. Penelitian Ilmiah, Kefilsafatan dan Keagamaan: Mencari Paradigma Bersama dalam Tradisi Baru Penelitian Agama Islam: Tinjauan antar Disiplin Ilmu. Bandung: Nuansa

Syalabi, Ahmad. 1982. Islam dalam Timbangan, Terj, Abu Laela \& Muhammad Tohir, Bandung: PT. Al Maarif

Tafsir, Ahmad. 2009. Ilmu Pendidikan dalam Perspektif Islam, Bandung, Remaja Rosdakarya, 2002.

Yusuf, Al-Qaradhawi. 2002. Fatwa-fatwa Kotemporer jilid 3, penerj. Abdul Hayyie alKattani, dkk, Jakarta: Gema Insani Press 